\title{
Temas que debería abordar la V Conferencia General del Episcopado Latinoamericano*
}

\author{
Pedro Trigo \\ Centro Gumilla \\ Venezuela, Caracas
}

\section{Introducción: no se puede acceder a la voluntad de Dios más allá de la com- plejidad de la historia}

Para ver qué pide Dios a la Iglesia latinoamericana habría que auscultar los signos de los tiempos. Porque ni la Biblia leída de manera fundamentalista, ni la doctrina cristiana y la normativa eclesiástica bastan para determinarlo. Son imprescindibles el juicio profético (lo que Dios pide a su pueblo, en una coyuntura determinada) y el sapiencial (lo que conviene hacer, según la mentalidad y las actitudes de Jesucristo). Pero no hay que olvidar la complejidad e incluso la opacidad de la historia. Por eso, es preciso hambre de realidad para no caer en ideologizaciones.

La conveniencia de usar este método viene dada, desde el punto de vista teológico, por la primacía del Espíritu para entrar en contacto con el Padre y el Hijo, y con su designio para nosotros. Y el Espíritu es la actualidad de Dios. El Espíritu, hablando en términos gramaticales, es verbo, no sustantivo. Es acción presente: el soplar del viento, el manar del agua, el crepitar del fuego, el cernirse del ave, el nacer, para usar los símbolos bíblicos. Él es el que nos interpreta las Escrituras, el que nos va guiando a la verdad completa, el que nos da a conocer

* Cuando el lector tenga en sus manos este número de la Revista Latinoamericana de Teología probablemente ya habrá tenido lugar la Conferencia de Aparecida. Publicamos este artículo, sin embargo, pues su importancia va más allá de la Conferencia. 
lo que está en ciernes. Por eso, el presente tiene primacía sobre el pasado. Pero no el presente en cuanto situación, estructuras, instituciones, sino en cuanto que el Espíritu lo impulsa, desde más adentro que lo íntimo de cada uno, y de un modo global, aunque siempre, en definitiva, personalizado. A esa presencia alude el primer párrafo del n. 11 de la Gaudium et Spes. Por eso, la constitución conciliar dice que para cumplir su misión, la Iglesia tiene que tomarse el trabajo de escrutar, en cada época, los signos de los tiempos (n. 4).

La institución eclesiástica es proclive a caer en la ilusión de creerse que tiene a Dios disponible de modo, digamos, automático, en sus ritos, disciplina y doctrina. El ex opere operato, que para Agustín era un caso límite, indeseable pero posible, para asegurar el acceso de los fieles al sacramento, incluso en el caso de un ministro indigno, por lógica institucional y con ayuda del juridicismo del derecho romano, pasa a ser el paradigma. Así se cae en el cristomonismo, tan justamente criticado por la Iglesia oriental, en el que Cristo desemboca directamente en la institución eclesiástica, como potestas, un poder trasmitido de forma jurídica e independiente de la situación personal del que lo recibe. En este esquema no sólo no hay lugar para el Espíritu como movimiento personal transcendente y personalizador (que no puede equivaler a la potestas), sino que ese movimiento, siempre trascendente y libre, y siempre secundado libre y personalmente, estorba, porque es acontecimiento en el sentido más fuerte de la palabra y no mera actuación, digamos infalible, de una fuerza, de un poder.

Hoy, cuando disminuye drásticamente el número de los católicos practicantes dispuestos a aceptar esta cristomonía, en vez de revisarla y entrar en el camino humanizador y sinodal de la obediencia al Espíritu, se tiende, por una parte, (sobre todo en bastante clero joven y no pocos del aparato institucional) a afincarse en su autoridad institucional y, en definitiva, en el derecho canónico, y por otra (sobre todo en instancias centrales y en algún movimiento), en centrarlo todo en la Eucaristía, entendida, no ya como celebración de la vida cristiana, es decir como sacramento, sino como rito mistérico, que ellos controlan, en el cual se accede, de forma automática, a la divinidad. De nuevo se deja de lado al Espíritu: el derecho canónico, la doctrina autoritativamente codificada o el rito tornan innecesario el discernimiento. Más aún, el proceso de discernimiento complejiza innecesariamente el acceso a lo divino, lo vuelve incluso problemático, cuando los otros canales lo otorgan de una manera precisa e indiscutible.

Hoy, los intentos de buscar otros métodos que no comiencen por la realidad esconden siempre la propuesta de acceder a lo divino, más allá de la complejidad de la historia y del Espíritu, que la anima de modo personalizado.

Hay que reconocer que el tema de la V Conferencia, a diferencia de los anteriores, es muy preciso y esa concreción dificulta, en alguna medida, la aplicación del método. En efecto, si se comienza describiendo los núcleos problemáticos y las tendencias dinamizadoras, tanto en el ámbito mundial (en cuanto nos afectan) 
como en el regional, resulta un tanto forzado presentar a Jesús de Nazaret, a quien seguimos como discípulos participantes de su misión, como la solución de todo. Jesús, a diferencia de Moisés y Mahoma, no se presenta como quien, de parte de Dios, legisla minuciosamente cada uno de los aspectos de su sociedad. Él no entendió así su misión. Por eso, es inútil buscar en sus enseñanzas y actuación la respuesta pormenorizada a cada uno de los problemas, sin contar con que los asuntos de hoy son, en gran parte, desconocidos para su época. Así, pues, en la segunda parte (la iluminación teológica) habría que hacer ver que escuchar a Jesús y seguirlo, si lo hacemos desde la obediencia a su Espíritu, nos pone a la altura de la realidad y nos da las actitudes, el horizonte y la fuerza para que adquiramos las aptitudes que nos capaciten para responder superadoramente a las situaciones, asumiendo las mediaciones pertinentes y colaborando al unísono con todas las personas de buena voluntad, en quienes actúa el mismo Espíritu derramado en la pascua.

\section{Signos de los tiempos en América Latina hoy}

Veamos, pues, cuáles son hoy los signos de los tiempos y el discernimiento acerca de ellos. Comenzando por lo primero, éstos serían, a mi juicio, los signos de los tiempos que tenemos que discernir. Los dos primeros, que debemos abordar en forma conjunta, son la mundialización, como caracterización de la nueva época, y la plasmación institucional del carácter multiétnico y pluricultural de nuestra región, como caracterización de la nueva época latinoamericana.

Los signos de los tiempos, respecto del cristianismo, en nuestra región serían la solución de continuidad en la trasmisión social del catolicismo, el aumento exponencial del catolicismo practicante eclesial, el hambre de Dios y de religión compensatoria, sin religación, el paso del cristianismo como único horizonte de la región a la presencia real y sobre todo mediática de las demás religiones, la maduración de las minorías que asimilaron el Vaticano II, desde la recepción de Medellín y Puebla.

\subsection{Discernimiento de la mundialización}

La mundialización, como todo lo histórico, es ambivalente. Por eso, no se la puede demonizar, ni sacralizar. No es posible vivir al margen de ella, aunque sí trasformarla desde dentro, superadoramente.

La globalización es el resultado de la aplicación consecuente (es decir, extendida a todos los campos y sin contrapeso) de la razón instrumental para la cual todo es mesurable y debe ser optimizado. La dirección, dominante hasta ahora, de la mundialización es el totalitarismo de mercado. El mercado copado por las corporaciones mundializadas, cartelizado, eliminada la competencia en los grandes niveles y protegido con subvenciones y aranceles. Predominio despótico del capital financiero y de las corporaciones, sobre todo basado en la manera como se interpreta la normativa de la propiedad intelectual y la flexibilización del contra- 
to de trabajo, y del criterio de la no responsabilidad, por los efectos colaterales y los costos sociales. Cooptación de la democracia para que acepte esa normativa, desventajosa para la mayoría, con el argumento capcioso de la inexorabilidad. Unilateralización de las personas y la vida social, centradas en producir y consumir. Todo esto deshumaniza a quienes lo imponen y a quienes se someten a ello, y, además, sobreexplota a muchos y excluye a la mayoría.

El totalitarismo de mercado pretende el fin de las entidades colectivas y de los sujetos personales. Para el mercado todo se reduce a entidades privadas, que contratan y que se definen por las reglas de juego. El acceso inmediato a todo por la televisión, y sobre todo por internet, hace plausible la impresión de que cada individuo tiene a la mano todos los elementos para participar en el juego propuesto. Pero esta impresión de autonomía y autosuficiencia no equivale a la constitución del sujeto personal, ya que un ser así es sólo un elemento del conjunto, que le brinda tanto las posibilidades como las limitaciones.

La Iglesia latinoamericana no puede limitarse a paliar los efectos más estridentes del totalitarismo de mercado. Es indispensable que denuncie el modelo en sí, por las razones aludidas. No hacerlo, es signo de infidelidad al Dios de los excluidos y de la humanidad, y de sumisión al dios de este mundo del que se reciben dádivas para numerosos programas y a quien se teme por su inmensa capacidad para desprestigiar y excluir.

Sin embargo, esta época posee bienes civilizatorios y culturales que nos potencian enormemente. Ante todo, el propio mercado, que es el modo más justo ideado por la humanidad para distribuir los frutos del trabajo social. Cuando se lo libere de la distorsión corporativa, se lo reduzca a su campo propio (ya que no todo se puede comprar ni vender, por ejemplo, los elementos o lo estrictamente humano, como el amor) y se corrijan políticamente sus distorsiones, se verá su fuerza dinamizadora.

La innovación más trascendente es la genética, aún en ciernes, que, a través de la ingeniería, va a revolucionar superadoramente la medicina, si logramos vencer la tentación de la manipulación genética, en la cual ya se ha caído.

La innovación de fondo son los circuitos integrados, que han posibilitado todas las demás innovaciones.

La innovación más patente e impactante es la simultaneidad: el espacio no está ya en función del tiempo. La caracterización del ser humano como ciudadano del universo tiene hoy contenidos analíticos concretos y los tendrá cada vez más. Para nosotros se tiene que convertir en la expresión histórica de la fraternidad de las hijas e hijos de Dios, que es nuestra última realidad, a la cual deben referirse las demás, desde la familia a la ciudadanía de un país, pasando por la pertenencia a una cultura o a diversas instituciones, incluida la institución eclesiástica. Así lo vislumbró ya la Gaudium et Spes. 
Para los medios de comunicación, controlados por unas pocas agencias, el mundo no occidental es lo ancestral y exótico, lugares no normativizados aún, donde todavía sucede lo pintoresco (restos del pasado para consumo turístico) y escenario de catástrofes naturales, sociales y políticas, o el destinatario de la ayuda de occidente, o la muestra de cómo la occidentalización en ciernes produce la superación humana y el desarrollo. No se lo considera como lo diferente, dotado de sustantividad, dinamismo propio y dignidad.

Al verlo todo desde el paradigma occidental, el mismo que se inculca en la educación, la economía y la política a su servicio, se nos insta a hacer nuestra esta perspectiva, no sólo para mirar lo otro, sino para mirarnos a nosotros mismos. De este modo, nosotros los latinoamericanos somos los que no acabamos de ingresar en la normalidad occidental, ya que el occidente es lo común, porque sería el destino de toda la humanidad. Los de otros continentes son los que están todavía más alejados del canon de humanidad deseable, aunque China, India y los tigres asiáticos, en medio de su exotismo, están caminado en esa dirección incomparablemente más rápido que nosotros.

Desde esta perspectiva de la globalización dominante, el destino es ir siendo iguales y competidores. La homogeneización nada tiene que ver con las relaciones simbióticas, con el reconocimiento mutuo y con la fraternidad. El otro es un posible mercado, donde desembocan nuestros productos, o un posible competidor; nunca otro ser humano con quien compartir y convivir, enriqueciéndonos mutuamente. Por eso, la oportunidad concretísima de vivir la fraternidad universal, que nos ofrece esta época, pasa por desmarcarse de la dirección dominante de la globalización y caminar hacia una mundialización alternativa. Esta propuesta ha de estar muy presente, empezando por cada país y por la región latinoamericana y debe caracterizarnos como cristianos.

Además, la información computarizada es de suyo abierta (la autopista de la información), disponible a todos los seres humanos (la proliferación de las computadoras es cuestión de pocas décadas). Así, es técnicamente posible diseminar el conocimiento que posibilite la democracia.

La computadora, manejada desde una perspectiva liberadora, es una herramienta imprescindible. Es capaz de romper el aislamiento de zonas rurales y de periferias suburbanas. La experticia en su manejo hace posible desde la capacitación en todas las áreas hasta la alimentación espiritual más cualitativa y la planificación pastoral más exigente y compleja. La diseminación de su uso no sólo es imprescindible para que los pobres se pongan al día en todas las áreas, adquiriendo así el capital más apreciado en esta sociedad del conocimiento. Y también para constituir sujetos colectivos virtuales, capaces de estar a la altura de los retos pastorales y sociales. Para esto es imprescindible la colaboración con profesionales competentes, teniendo en cuenta que la cultura suburbana es una cultura contemporánea, sensible hacia estos instrumentos. 
La simultaneidad ha propiciado que se configuren redes mundiales para corregir las actuales distorsiones, mediante la impregnación cultural alternativa, y para ejercer presión sobre las corporaciones y los estados cooptados por ellas, y sobre todo para establecer una cultura de la democracia, de los derechos humanos y de la vida, que propicie una democracia mundial.

\subsection{Discernimiento de la tercera época latinoamericana}

Estamos arribando a la tercera época de nuestra región, después de la época amerindia y de la época de los peninsulares, devenida finalmente, por efecto de las migraciones, en época de los occidentales. Esta segunda época tuvo tres períodos: en el primero, los peninsulares afincados aquí y los venidos temporalmente de allá compartieron el poder como parte de la administración o para "hacer la América". En el segundo, los afincados aquí se emanciparon de los de ultramar, constituyéndose en los únicos señores de indios, negros y castas. El tercero fue el tránsito de las repúblicas señoriales a las democracias de masas, al dar paso a posiciones de poder económico y político a personas de otras etnias, previa occidentalización, por la vía de la educación y la participación política.

La tercera época está adviniendo, cuando un número creciente de personas de etnia no occidental busca asumir los bienes civilizatorios y culturales de occidente, pero no ya para dejar su identidad cultural, sino para ejercerla con mayor solvencia y prestancia. Lo más visible es el pujante y cada vez más maduro movimiento indígena pero, a la larga, tendrá tanta o más fuerza el mestizo y, en ciertas regiones, el afrolatinoamericano. La inestabilidad de la región no cesará hasta que los occidentales den lugar a los otros, de manera que la realidad multiétnica y pluricultural que nos caracteriza, se exprese también en las instituciones, es decir, hasta que América Latina, deje de ser sólo latina para ser, además, indígena, mestiza y afrolatinoamericana. Pero no como coexistencia pacífica, sino en interacción simbiótica.

Por ahora no se ve que los occidentales dominantes estén dispuestos a dar lugar a las otras culturas. No se ve que la cultura predominante deje de ser institucional y ambientalmente latina. Están dispuestos a cualquier cosa para que eso no llegue a suceder. Somos, y cada vez seremos más, una región dividida. Mientras no se dé lugar a las demás culturas, sólo por la fuerza se mantendrá la unión. Y cuanto más se demore el proceso, más se endurecerán los contendientes.

Dar lugar a los hasta hoy preteridos y subalternos es un acto elemental de justicia, que todo el que aspire a una congruencia cristiana elemental no puede sino apoyar, sea cual sea el costo que le suponga. Pero también es el reconocimiento de su prestancia histórica, de la capacidad de resistencia de sus culturas y de la riqueza de que todos se expresen en todas las dimensiones de la vida social. No verlo, es vivir en un etnocentrismo empobrecedor, indigno de un cris- 
tiano, cuya calidad se mide, no por el amor al prójimo, sino por la aproximación al distinto, que mi cultura tiene como inferior.

Hay que reconocer que, así como la izquierda ha luchado históricamente en América Latina por la superación del pueblo a nivel económico, social y político, ha desconocido la dimensión cultural, por confinarse dentro de la dialéctica de la ilustración, que es eurocéntrica, es decir, occidentalizadora.

Es de justicia admitir que desde Medellín y Puebla, el catolicismo ha contribuido significativamente al surgimiento de todo tipo de grupos de base, es decir, a que mucha gente popular crezca en su condición de sujeto personal y social, espiritual y cultural. La propuesta de "alentar y favorecer todos los esfuerzos del pueblo por crear y consolidar sus propias organizaciones de base" (Medellín 2,27 ), es una propuesta de envergadura histórica, no sólo porque supone creer realmente en el pueblo sin mediatizarlo por el partido y el líder, como hacían el populismo y el socialismo, sino porque se plasmó en una medida bastante notable. Podemos decir que, hasta hoy, muchas de las fuerzas que luchan por una América multiétnica y pluricultural se han fogueado en grupos de inspiración cristiana y saben que pueden contar como aliada a gente de Iglesia organizada.

Pero también habría que reconocer que hasta hoy en día, la institución eclesiástica es occidental (occidental americana, por supuesto) y no ha aceptado una institución eclesiástica indígena, ni negra, ni mestiza, en comunión mutua y con la de la cultura occidental americana. Como las demás instituciones, está reaccionando con reflejos de defensa ante lo que percibe como amenaza. Nos tendríamos que preguntar si inconscientemente no se está negando a expresarse como Iglesia católica, en el sentido de configurada según el paradigma de Pentecostés. También en América Latina hoy es preciso que las maravillas que Dios obró en Jesús y las que sigue obrando con su Espíritu se proclamen, en las diversas lenguas y culturas. Pero además del problema de la fidelidad, habría que estar claro en que, si la institución eclesiástica es percibida por estas culturas emergentes como una de las fuerzas que, por obstinarse en conservarse sólo como occidental, se opone a que se afiance esta nueva época, será barrida junto con las demás. Ya empiezan a notarse síntomas de esta fractura. Tenemos un tiempo muy limitado para que no ocurra esta catástrofe. Catástrofe para la Iglesia y para la región.

Se nos hace muy cuesta arriba reconocer que, hasta hoy, Iglesia e institución eclesiástica son lo mismo para el pueblo latinoamericano, porque la institución eclesiástica siempre ha sido exterior a él, en el sentido de que nadie del pueblo pertenece a ella. Hay muchos de origen popular, pero esta expresión significa precisamente que, habiendo nacido en el pueblo, ya no son de él, por cultura, ni por pertenencia. Así se explica el surgimiento del catolicismo popular que, como reconoce Puebla, no es una variante devocional (como hoy sostienen muchas instancias eclesiásticas: piedad popular), sino otra versión del catolicismo, 
distinta a la de la institución eclesiástica, aunque no en competencia con ella, sino reconociéndola, pero siempre dentro de su propio esquema. Esta inculturación del evangelio que es el catolicismo popular, como reconoce Santo Domingo, ahora debe expresarse también en el nivel institucional, tanto en las expresiones de cada una de las culturas populares (indígenas, afrolatinoamericana, campesina, suburbana), como en sus personeros, con todo el cuidado del caso, pero decididamente, no sólo mediante diáconos, como se ha hecho hasta ahora de forma tímida, sino presbíteros y, con el tiempo, obispos.

\section{La contribución del catolicismo pasa por su re-creación}

Sólo si entramos de manera decidida en la tercera época latinoamericana, estaremos en condiciones para asumir la mundialización, no de modo apendicular y mimético, sino aportando nuestra riqueza y así podremos exigir nuestro lugar. El catolicismo puede seguir aportando, desde el espíritu de la encarnación kenótica y solidaria que floreció a partir de Medellín y Puebla. Espíritu que debe ser reavivado, con las trasformaciones que exige esta nueva época mundial y latinoamericana. Pero debe contribuir, dando ejemplo, con su diversificación institucional, en intercambio simbiótico (cristianamente hablando, en comunión), a las demás instituciones políticas, culturales y económicas, a las cuales el tiempo demanda con urgencia esta diversificación.

Al discernir el mercado, mencionamos la dificultad de que en América Latina surjan y se desarrollen verdaderos sujetos humanos y la trascendencia de que proliferen. No creemos que exista hoy en la región ninguna institución que pueda ayudar eficazmente a que se autoproduzcan, ni que esté interesada en ello. El cristianismo es la fuerza histórica más capacitada para ayudar a que se den estos sujetos humanos, es decir, seres que liberen su libertad, en la entrega solidaria a otros seres humanos, excluidos o necesitados de uno u otro modo.

Pero también la fuerza histórica del cristianismo en América Latina necesita liberarse. En esta coyuntura estamos. El cristianismo es casi indispensable para que América Latina entre en su tercera época, es decir, que no se fraccione por etnias, sino que se dé un reconocimiento mutuo, que se traduzca en una interacción simbiótica, que la ponga en condiciones de situarse a la altura del tiempo, es decir, de la mundialización. Pero para que sea capaz de desempeñar ese papel histórico, necesita recrearse superadoramente. Necesita pasar de ser una Iglesia sociológica a una Iglesia de convertidos, y de convertidos específicamente a Jesús de Nazaret, por un encuentro personal con él, que trasforme su vida.

Nuestra Iglesia no es la que Puebla llama la de los fundadores. Es la Iglesia postridentina, centrada en la doctrina, el rito y las devociones. Una Iglesia de clérigos que atendían a la masa de fieles, equiparada a la de los ciudadanos. Una Iglesia mantenida por la costumbre, que era ley introyectada. Pero hoy, la realidad va en otra dirección. Hay un aumento exponencial de católicos practicantes 
a-eclesiales. Por efecto de la solución de continuidad entre las generaciones, las nuevas ya no son, salvo minorías, cristianas. Y el crecimiento acelerado de cristianos no católicos hace ver que esa Iglesia ya no es posible, además de que no es voluntad de Dios.

Queremos insistir en este punto, porque tenemos dificultad casi insuperable para digerirlo. La Iglesia latinoamericana actual, concebida todavía como Iglesia de masas, además de no ser voluntad de Dios, se va a ir diluyendo, hasta casi desaparecer. Este diseño eclesial concibe a la mayoría de los católicos como gente con escasa conciencia de su ser cristiano y eclesial, con muy poco conocimiento del cristianismo y con una práctica cristiana poco consecuente. Cristianos con este perfil necesitan una Iglesia concebida como un recinto, que proteja su poca fe, y necesitan unos pastores, fuertes en la fe y esclarecidos, que los tutoreen. Esta Iglesia era la versión a lo divino de una sociedad patriarcal, y en el fondo, señorial, en la que unos pocos concentran toda la iniciativa y responsabilidad y, en definitiva, todos los derechos, mientras que la gran masa no tiene más posibilidad que obedecer a sus dictados y recibir su protección y sus dádivas. Una Iglesia así, repetimos, no es sacramento del reino, sobrevive como un anacronismo y dentro de poco, se convertirá en una magnitud residual.

En efecto, el mercado religioso mundializado se ha refractado enormemente, y cada vez va a ser más frecuente el caso de gente que busque, por sí misma, la oferta que más le cuadre. Estas personas no sienten ningún tipo de fidelidad hacia la Iglesia católica. Pero incluso quienes siguen identificándose como católicos, cada vez tienen menos sentido de pertenencia institucional. Bastantes latinoamericanos valoran todavía lo religioso, incluso lo cristiano, pero, por eso mismo, quieren ser plenamente sujetos y no doctrinos o meros destinatarios.

Estas personas sólo serán católicas mediante una propuesta fuerte de encuentro personal con Jesús de Nazaret, que trasforme sus vidas. Pero esta propuesta sólo puede acontecer en una Iglesia, no de masas y minorías, sino de convertidos, de testigos, de cristianos adultos, que se hacen cristianos juntos y se llevan mutuamente en su fe, en su amor fraterno y en su vida cristiana.

Si el párroco es el que manda, en definitiva, es el único sujeto, y los demás son meros destinatarios, o a lo más, sus colaboradores (y este modelo lo avala el Derecho Canónico), esa parroquia se va a quedar sola. Sólo una comunidad de convertidos puede ser una comunidad de hermanos. En cualquier otro caso tenemos, como hasta hoy, una Iglesia de padres e hijas e hijos. Esta Iglesia no es voluntad de Dios, pero además, se va a derrumbar como un castillo de naipes. Si como curas no nos vemos en una Iglesia de hermanos, nos vamos a convertir en unos caciques sin indios o en oficiales sin soldados. Conviene tener muy claro, no sólo en qué se juega nuestra fidelidad sino por dónde va la dinámica histórica. 


\section{Ejes del cambio: encuentro trasformador con Jesucristo, centralidad de la palabra de Dios, y llevarnos mutuamente}

La conversión que da lugar a cristianos adultos no será una conversión a la doctrina cristiana, ni a la disciplina eclesiástica, sino al Jesús de los evangelios. Un Jesús que nunca ha sido proclamado por la Iglesia postridentina latinoamericana, la cual sólo ha puesto a la gente en contacto con él, por la vía ritual: Navidad y Semana Santa. Es obvio que Jesús resucitado ha estado presente de múltiples modos en la historia cristiana de América Latina. También se dio algún conocimiento de Jesús a través de alusiones en sermones, devocionarios y cantos, pero no se entregaron los evangelios como tales, ya que ni siquiera estaban traducidos, y el uso de la Biblia estaba reservado a los clérigos. Por tanto, no se entregó la historia de Jesús, su narratividad, tal como quedó plasmada en los evangelios, por inspiración del Espíritu.

El movimiento bíblico fue aceptado y difundido por el Vaticano II, pero no llegó masivamente a América Latina, sino a raíz del impulso de Medellín y Puebla, y por el vehículo, sobre todo, de las comunidades eclesiales de base. Sin embargo, la posesión y el uso habitual de la Biblia, por parte de la gente, todavía se asocia a los evangélicos. Urge que la Iglesia latinoamericana, al más alto nivel, proclame como línea de acción prioritaria la entrega de la Biblia -sobre todo, los evangelios que son su corazón- al pueblo como acto de tradición constituyente. Constituyente, porque la Iglesia se constituye en obediencia a la Palabra, y por eso, nuestra Iglesia no estará plenamente constituida hasta que la palabra evangélica no sea la fuente de nuestra espiritualidad y pastoral, mediante la lectura orante, personal y comunitaria, y mediante homilías que desentrañen lo que la palabra dice y lo que nos dice a los cristianos de hoy.

La pregunta sobre cómo y dónde encontrarnos hoy con el Señor ofrece respuestas muy diversas en nuestra Iglesia. No todos los caminos llevan a Jesús de Nazaret. Los hay que llevan a un Cristo pietista, deshistorizado, a un Jesús concebido como el Amigo, que suscita emociones intensas, pero que carece de rasgos propios. A ese Cristo le pone cada uno el rostro que más le cuadra, o el rostro trascendentalizado de quien lo propone, sea persona (el pastor, en iglesias libres evangélicas, o el líder de un grupo apostólico o de una comunidad cristiana) o institución (la doctrina de un movimiento apostólico o de una instancia de la institución eclesiástica).

Hoy está tomando mucha fuerza de nuevo la corriente de la teología de los misterios, que estuvo a la base de la renovación litúrgica, que antecedió al Concilio y que se expresa, hasta cierto punto, en Sacrosanctum Concilium. Según esta propuesta, a Jesús se lo encuentra del modo más vivo y denso en la liturgia, sobre todo en la eucaristía. Ella sería el corazón de la Iglesia. Lo demás debería entenderse como preparación para este encuentro o como su fruto. 
No estamos de acuerdo. Hay que insistir, en primer lugar, que Jesús "no está aquî": esperamos su venida y vamos a su encuentro. Por eso, debemos estar en vela y cumplir el encargo recibido, que no es otro que la prosecución de su historia, la vida como seguimiento. Seguimos a quien fue llevado al cielo y está sentado a la derecha de Dios.

Nuestra vida, como la de Jesús, debe estar focalizada por el reino: recibir el reinado (fundar nuestra vida en Dios, que en Jesús se ha constituido para nosotros en Padre materno, y obedecer el impulso del Espíritu) y vivir al servicio del reino (el establecimiento del mundo fraterno de las hijas e hijos de Dios). Según esto, nuestra fidelidad se juega en la vida. La vida es el lugar en el cual basamos nuestra vida en el Padre materno, o en el tener o el poder, y en el cual construimos relaciones de fraternidad y estructuras e instituciones que la vehiculen, o nos portamos de modo autocentrado y buscamos nuestros intereses, insensibles a los demás. Esta vida es la que se celebra en los sacramentos, sobre todo en la eucaristía, cuando la vivimos como auténticos seguidores de Jesús. Según esto, lo fundamental del cristiano no acontece en ritos, sino en la vida. Y esta vida se sacramentaliza en símbolos, entre ellos, los sacramentos.

Quiero insistir, para que no se malinterprete mi pensamiento, que desde la perspectiva que sostengo, la eucaristía es siempre una experiencia hermosa y revitalizadora. Cuando una comunidad viva y abierta estructuralmente a los pobres, muchas veces formada en su mayoría por pobres, se reúne como hermanos y hermanas y escucha discipularmente la Palabra, la comunión sacramental con Jesús expresa realmente esta comunicación en fe, que constituye a cada uno como discípulo y que hermana a la comunidad y la envía a sus vecinos y conciudadanos. Cuando la cena del Señor no es un rito atemporal y fijo, sino un símbolo vivo, alimenta y une. En realidad, es una fiesta que compromete y anticipa el banquete del Reino.

Así, pues, a Jesús de Nazaret lo conocemos mediante el testimonio de los testigos, que lo testifican con su vida y su palabra, porque la fe entra por el oído. Ellos nos lo presentan en los evangelios, que leen desde su vida de discípulos y escuchan, abriéndose a ellos, para que ellos lean su vida, para vivirla cada vez más en fidelidad creativa. La entrega a este Jesús, creído en la comunidad de discípulos, se expresa en los sacramentos, porque los seres humanos somos animales simbólicos y porque estos signos se remontan al propio Jesús. Pero se realiza en la vida, vivida como seguimiento: teniendo una relación con nuestra situación equivalente a la que tuvo Jesús con la suya. Así entendemos el encuentro salvador con Jesús de Nazaret.

Sintetizando. El encuentro con el Señor, para convertirnos a él, se realiza a través de la escucha de la Palabra: la fe entra por el oído. Este encuentro se realiza en la vida. La vida no es un mero campo de aplicación, sino el lugar primigenio donde nos relacionamos con Dios, donde seguimos a Jesús y secundamos 
el impulso del Espíritu. Esta entrega se celebra en los sacramentos, señaladamente en la eucaristía.

Por eso, pasar de una Iglesia sociológica a una Iglesia de discípulos y testigos conlleva la entrega de los evangelios -y desde ellos, el resto de la Bibliacomo acto de tradición constituyente. Ésta no se da por el estudio de la Biblia, convenientísimo por otra parte, sino cuando la Palabra se proclama a sí misma, como señora, a los discípulos, entre los que se cuenta el que la proclama, que también debe escuchar y no sólo recordar lo que sabe, y por la lectura orante, personal y comunitaria.

Esta conversión a Jesús de Nazaret se expresa en su seguimiento. El seguimiento no es una relación, sino una correlación: Jesús es a su situación como nosotros a la nuestra. La equivalencia exige conocer, tanto la relación de Jesús con su época, por una lectura no ingenua, ni fundamentalista de los evangelios, como un conocimiento serio de la nuestra. En caso contrario, se proyecta nuestro horizonte de comprensión sobre los datos del evangelio, desconociendo que tienen que interpretarse en su propio horizonte y para establecer luego un diálogo de horizontes. Y desconociendo también que el establecimiento de la equivalencia requiere la creatividad fiel como actitud y la obediencia a la moción del Espíritu, que Jesús nos dejó como intérprete. Este método nos lleva a la realidad donde se construye el sujeto, nos encontramos las personas y se transforma superadoramente la historia.

De esta escucha obediente de la Palabra evangélica, leída desde la vida, surgirán comunidades de condiscípulos que se llevan mutuamente en la fe, en el amor fraterno y en la vida cristiana. En este nivel primordial, todos en la Iglesia, desde el papa al último bautizado, somos discípulos y condiscípulos. Cuando nos enseñemos unos a otros, cuando nos ayudemos unos a otros, cuando nos corrijamos y soportemos unos a otros, en suma, cuando nos amemos concretamente unos a otros, se hará patente la condición de la Iglesia como sacramento de la unión del género humano.

Estas comunidades serán levadura para que en América Latina se dé, por fin, el reconocimiento, como riqueza para todos, de la multietnicidad y la pluriculturalidad, y para que, desde ese reconocimiento, nos abramos al reconocimiento de las otras regiones del mundo y a la colaboración simbiótica con ellas, hasta el establecimiento de una democracia planetaria.

En esta época de mundialización, estamos entrando en contacto habitual con personas de otras religiones, tanto las ancestrales de América Latina como las africanas, traídas por los esclavos, que se fueron trasmutando con el paso del tiempo, como el Islam y las grandes religiones asiáticas. En esta situación, nos son presentados muchos Cristos, muchos ungidos con el Espíritu de Dios, muchos mediadores, muchos hijos de Dios. Incluso llega a decirse que todos lo somos por 
creación y que esos grandes iluminados son maestros, porque han comprendido con absoluta clarividencia lo que implica la condición de hijo de Dios y nos lo han explicado para que, también nosotros, nos percatemos de nuestra condición y obremos en consecuencia. Estamos, pues, en una situación bastante parecida a la de la primera difusión del cristianismo, que fue también una época globalizada, en la cual coexistían religiones y cultos, no pocas veces en interacción.

Se nos dice que en esta situación no es ya sostenible el carácter escatológico de Jesús. Y, si no lo es, ¿por qué centrarlo todo en el discipulado de Jesús? Este tema es inevitable, tanto porque está planteado en el nivel teórico, como porque mucha gente prueba por un lado y otro, pretendiendo que todo se puede mezclar, y que el sujeto es el único punto de referencia absoluto, siendo lo demás algo relativo, que debe tomar o dejar, según le ayude. El "todo es para ustedes", que decía Pablo a los corintios, hoy lo entienden no pocos cristianos de modo absoluto, y no como Pablo, que añadía, "pero ustedes son de Cristo y Cristo es de Dios" (1Cor 3, 21-23).

En esta situación, de coexistencia de religiones y no pocos veces de sincretismo, la V Conferencia debe proclamar a Jesús como el que nos revela a la vez a Dios y a nosotros mismos porque es el Hijo único de Dios, quien, al asumirnos como sus hermanos, nos constituye en hijos verdaderos de Dios: hijos en el Hijo único. Él fue el que en la pascua nos envió a su propio Espíritu para que podamos decir a Dios Abbá, como lo decía él, y no menos para que podamos reconocer a Jesús como nuestro Señor.

Jesús no elimina a los demás mediadores, ni hace desaparecer todas las religiones. Los verdaderos creyentes, en todas ellas, nos enseñan aspectos concretos de Dios y, consiguientemente, de nuestra condición humana. Pero sólo Jesús nos revela a Dios como Padre, en el sentido estricto en que lo entendemos, y nos lo revela constituyéndonos en hijas e hijos suyos. Más aún, nos lo revela en los pobres y haciéndose él mismo pobre $(2 \operatorname{Cor} 8,9)$.

\section{Una propuesta incondicional de vida humana}

Hemos insistido en la primera parte en la necesidad de superar el totalitarismo de mercado, que propicia la sobreexplotación, la exclusión y la deshumanización. Ahora queremos insistir de modo complementario en que esa superación sólo será posible si adquirimos libertad respecto de él. La conversión a Jesús de Nazaret y la dedicación a proseguir su historia, en comunidades de hermanas y hermanos, abiertas estructuralmente a los pobres, proporciona esa libertad indispensable.

La Iglesia latinoamericana tiene que proclamar de manera inequívoca con su vida y con su palabra que siempre podemos vivir humanamente y con la felicidad que es posible en este mundo. Tenemos que empeñarnos con todas nuestras 
fuerzas para que mejoren las condiciones de vida, tanto nuestra capacitación como las oportunidades de trabajo y acceso a los servicios. Habrá, pues, que luchar sin descanso, en la trasformación de estructuras e instituciones, tanto en el nivel local como mundial. Pero, aunque esas condiciones pueden hacer muy cuesta arriba el vivir de modo humano o favorecerlo, siempre está en nuestras manos vivir con dignidad y contento de fondo, incluso en situaciones agudas de escasez, de exclusión o de dolor.

Vivir la vida fraterna de las hijas e hijos de Dios, está siempre en nuestras manos, por el Espíritu que Jesús nos dio. Y vivir esa vida da paz y dicha, da plenitud humana. En nuestro mundo, muchas veces el justo no puede vivir de su justicia, pero siempre puede vivir de fe, es decir, de esa relación filial con Dios y fraterna con las hermanas y hermanos. Esa relación da vida. Si no fuera así, el cristianismo sería pura ideología: otra manera de nombrar lo que todos viven, y no una vida nueva, una posibilidad de vida, ofrecida a todos de una manera absoluta, que, por tanto, nos constituye en verdaderos sujetos humanos. Sólo desde esa libertad, insisto, podemos luchar por trasformar superadoramente las condiciones de vida.

\section{La misión como evangelio inclusivo desde la encarnación kenótica en el único mundo}

Sólo una Iglesia de convertidos, es decir, de discípulos, puede emprender una misión realmente trascendente. Ya la conversión implica una trascendencia, porque el individuo se hace persona al aceptar la entrega de Jesús y corresponderle, y al aceptar a los hermanos que Dios le dio y entregarse a ellos. Pero la conversión lleva a la participación de la misión de Jesús, a proseguir su historia, animados por su Espíritu. La misión de Jesús es el reinado de Dios — aceptar a Dios como padre materno y a todos los demás como hermanas y hermanos- como camino hacia el reino — constitución del mundo fraterno de las hijas e hijos de Dios, hasta que él nos trasforme para formar parte de la comunidad divina y que Dios sea todo en todas las cosas.

La misión parte de la encarnación solidaria, en nuestra sociedad y en nuestra época. No se puede hacer desde fuera, desde una institución corporativizada, ya que lo que no se asume, no salva. Y tampoco se salva el que pretende salvar a algunos, llevándolos a su pretendido ámbito de salvación, separándolos del resto, que se da por perdido. Por eso, los cristianos, si somos congruentes, no podemos no estar a la altura del tiempo mundial y del tiempo latinoamericano, con el esfuerzo sostenido y el cambio de mentalidad que conlleva. No podemos confinarnos en nuestra comunidad, sino que tenemos que vivir lealmente, en nuestro mundo globalizado y en nuestra región latinoamericana y, como Jesús de Nazaret, echar la suerte con ellos. 
La encarnación, el santo y seña del Concilio, no es hoy la perspectiva, el horizonte y el ambiente que domina en nuestra Iglesia. Hoy vuelve la actitud preconciliar de considerar a la Iglesia, y dentro de ella a instancias corporativizadas, como el ámbito de la salvación. El mundo es lo anónimo, lo amorfo, lo no cualitativo: una tierra de nadie vacía, invivible. No tiene sentido encarnarse en el mundo y echar la suerte con él. Lo sensato es salvarse de él.

Hoy, esta propuesta, en muchos casos, nada tiene que ver con el rechazo al mundo moderno, característico del proyecto pastoral de restauración de la cristiandad. Es, por el contrario, un signo de la adaptación, sin discernimiento, a esta época, que no es ya la del capitalismo de la competencia abierta, sino la de las corporaciones que controlan no sólo el mercado, sino también sus reglas de juego para sus propios intereses. La corporación no tiene ninguna lealtad: trabaja para sí misma.

Da la impresión de que no pocas instancias eclesiales, dando por perdida la masa o al menos prescindiendo de ella, construyen ámbitos en los cuales los afiliados encuentran una identidad y un hogar y también una tarea, limitada pero que parece cualitativa. Por ejemplo, daría la impresión de que no pocos movimientos juveniles cristianos lo que hacen, en concreto, es sacar a sus afiliados de su generación y darles un lugar en la vida y una identidad. Lo mismo podríamos decir de movimientos de matrimonios o de educadores. Ejemplificando lo que queremos decir, en el caso de los educadores, la propuesta no es tanto contribuir a la trasformación de la educación y, más en concreto, del educador, su función y sus relaciones con el resto de la comunidad educativa, sino hacer todo eso en su propio ámbito específico, sin vínculos estructurales con los demás educadores. En bastantes casos no se ve que el trabajo se conciba como levadura dentro de la masa, sino como un ámbito privilegiado de selectos.

No es éste el estilo de Jesús, quien contrastaba con el sectarismo de bastantes de los grupos organizados de su tiempo. No es ésa su propuesta. Hoy, en la época de la mundialización, tenemos que volver a insistir, en contra del corporativismo ambiental, en la encarnación leal en nuestro mundo.

Esta encarnación, que supone una pertenencia, tiene como ámbito privilegiado a los pobres. La opción no es por los más pobres, sino por los pobres, por los que están entre las necesidades mínimas y las básicas, quienes, en parte están excluidos y, en parte, cargan el mayor peso. Sólo ellos pueden ayudar eficazmente a los que viven en la llamada cultura de la pobreza.

Una comunidad cristiana que no está estructuralmente abierta a los pobres, no es cristiana, ni siquiera celebra la eucaristía. Sólo desde los pobres se puede salvar a todos. Esto es frontalmente opuesto a la dirección dominante de esta figura histórica, que está dominada por la arrogancia arrolladora del capital, que ignora a los que no tienen capacidad de compra, ni capital humano disponible para ser empleado. Aquí está hoy lo que Pablo llamaba la locura de la cruz. 
Opción por los pobres no es convertirse en intermediarios de las corporaciones mundializadas, para paliar los efectos más desestabilizadores de sus políticas. Pasa por que los pobres sean sujetos en la sociedad y en la Iglesia. Eso quiere decir que tenemos que contribuir al cambio estructural mundial, y que, por su parte, la Iglesia tiene que reestructurarse desde los pobres con espíritu, que son su corazón.

La cuestión de crear trabajo productivo tendencialmente para todos y no considerarlo como una mercancía, es quizás la más relevante.

Hoy, en vez de optar por los pobres, por las grandes masas de pobres y por su constitución plena como sujetos en la Iglesia y en la sociedad, con el cambio estructural que esto supone y conlleva, la tendencia lleva más bien a enfrentar las llamadas nuevas pobrezas. Es cierto que éstas, por su tremenda estridencia, hieren mucho la sensibilidad humana y mueven a hacerse cargo de ellas, de modo perentorio. Estamos de acuerdo con la calidad cristiana de esta opción. Pero estamos en completo desacuerdo en que ella sustituya a la opción por las mayorías empobrecidas y excluidas. Estas mayorías son las abandonadas por la dirección dominante de esta figura histórica. Ni el Estado, ni los partidos, ni los sindicatos, ni los intelectuales se ocupan de ellos. En cambio, las corporaciones mundializadas contemplan cuantiosas ayudas para atender a los nuevos pobres, porque con ello lavan su imagen y se ganan el aprecio de la "gente decente", que no quiere ver en los espacios públicos de las ciudades espectáculos deprimentes que, además, son fuente de inseguridad. Para ellas, es una operación cosmética y de profilaxis social, aunque para los comprometidos en ella sea un acto de genuina misericordia.

No estamos de acuerdo con esta sustitución por dos razones. Ante todo, porque estas nuevas pobrezas están provocadas por el abandono de los pobres, por el Estado y la sociedad. En vez de atenderlas, para que no desestabilicen la sociedad y para aumentar la calidad de vida de los ambientes ciudadanos, invisibilizando lo que los afea y torna inseguros, lo que habría que procurar es quitar sus causas, y el único modo para hacerlo es elevar la capacitación, los empleos productivos y la participación efectiva de las mayorías, que son pobres. Además, el dinero de las corporaciones no basta para rehabilitar a estas personas. Sólo los pobres pueden acogerlos y reanimarlos para que se rehagan. Pero para que estén en condiciones de hacerlo, hay que ayudarlos a ellos.

La segunda razón por la que no estoy de acuerdo es porque me parece criminal abandonar al pueblo, como se viene haciendo, es decir, a los que están, no fuera como las nuevas pobrezas, sino adentro, pero en el lugar más bajo, cargando con el peso de todo y, además, desprotegidos. No es cristiana la sensibilidad sobreexcitada por las nuevas pobrezas, cuando coexiste con la insensibilidad ante la suerte de las mayorías. Ellas tienen que sentir, no sólo que los cristianos 
estamos con ellas, sino que ellas son nuestro lugar social y espiritual, nuestra casa, que la Iglesia tiene su figura y que, desde ella, atiende a todos.

Pero complementariamente, el privilegio de los pobres es para la salvación de todos. Esto es lo que significa que Dios no quiere la muerte del pecador, sino que se convierta y viva y que Jesús vino a llamar a los pecadores y murió pidiendo por ellos, y en su nombre, se predicó la conversión, que lleva a la vida. La misión no es neutral: se hace desde los pobres. Pero no acepta la polarización, no es sectaria. Busca irrevocablemente la conversión de los opresores a la fraternidad como una buena nueva para ellos. En la mundialización alternativa que proponemos, que salvaguarda la competitividad del mercado y la complementa con la seguridad social, mediante la democracia local, nacional, regional y mundial, hay espacio para todos. Todos tenemos que cambiar y pagar el precio, pero humanamente, todos salimos ganando.

Esto significa que, si rechazamos que los cristianos cambiemos de oferta para adaptarnos a los gustos de la demanda, aceptamos del mercado, sin embargo, el que la misión tome la forma de una propuesta, no de un emplazamiento, ni de una imposición moral. Una propuesta abierta, entre las muchas propuestas, porque estamos convencidos de que sólo una propuesta dirigida a la libertad es digna del evangelio y de las personas, y porque sabemos que es la mejor propuesta posible. Por eso, no hacemos misiones como operativos o campañas, no hacemos marketing, en el sentido usual de vender a toda costa una mercancía, condicionando a los destinatarios, para que tengan adicción a ella. Nuestra propaganda es nuestra vida de testigos y la levadura de nuestras comunidades. Desde ahí, tienen peso nuestras propuestas societales y nuestra proclamación de Jesús y del reino, que tiene que hacerse explícita y sistemáticamente.

Tenemos que reconocer que el ambiente nos lleva por la pendiente inclinada de una misión al estilo de las grandes campañas, que emprenden las corporaciones, para posicionar sus productos. Gente de peso en la Iglesia, que vive con angustia la pérdida de relevancia de la institución eclesiástica, que siente en carne propia la responsabilidad de hacer algo eficaz que consiga revertir la tendencia, se puede sentir inclinada a embarcarse en algún montaje en grande, como los que están viendo constantemente en las grandes empresas mundializadas, cuyo éxito es tan fácil de medir e incluso tan previsible. Seguramente, sus amigos empresarios y publicistas los animan a emprender ese tipo de acciones y se brindan a prestar ayuda o, por lo menos, asesoría. Es una tremenda tentación en la que, si Dios no lo remedia, vamos a caer y de la que podemos salir muy mal parados.

Para discernir esta cuestión tan espinosa, hay que partir del axioma de que "el modo de producción determina el producto". Como está muy comprobado en las Iglesias electrónicas, esas campañas logran éxitos contantes y sonantes, en cuanto al flujo de personas que asisten y al dinero que dejan en sus arcas. Pero ¿qué tiene que ver eso con el encuentro personalizador con Jesucristo, en 
orden a una transformación personal y a un cambio estable de vida? Si lo que se pretende es que muchos cristianos se movilicen, llevando propaganda, para que las iglesias vuelvan a estar llenas, sí pueden ayudar ese tipo de campañas. Pero un encuentro personalizador con el Señor, sólo se puede propiciar mediante encuentros personalizadores entre evangelizadores y evangelizandos. Es decir, no mediante operativos, mediante proyectos puntuales y objetivados, sino mediante procesos interpersonales, sean de individuo a individuo, sean grupales o también multitudinarios. Éstos no se excluyen, pero tienen que ser personalizadores y como fruto maduro de los otros dos tipos de encuentros. Jesús practicó los tres. Pero nunca a base de slogans, sino siempre dando que pensar, propiciando procesos abiertos, en los cuales la gente no era un mercado para conquistar, sino sujetos a quienes se ayudaba a personalizarse y a elegir libremente. Para Jesús, era menos malo un mal uso de su libertad que su secuestro, mediante cualquier tipo de coacción.

Así, pues, el problema no es el uso de los más modernos recursos de mercadeo. El problema es utilizarlos con el espíritu con que se los utiliza, que es lograr, no decisiones libres, sino reacciones automáticas ante estímulos, lograr adictos en el mismo sentido que decimos de la droga, para lo cual hay que dirigirse directamente a las pulsiones y deseos elementales, descomponiendo a la persona y reduciendo su capacidad de actuar desde la libertad responsable. Para lograrlo se actúa a base de iconos y slogans publicitarios.

Traducido al tema de la misión, se dota a los enviados de materiales muy sumarios y de instrucciones muy precisas sobre cómo emplearlos y relacionarse con los destinatarios, incluso se los provee de un mismo tipo de vestuario o, por lo menos, de algo que los identifique. Con este procedimiento, se eslabonan pasos que desemboquen en concentraciones cada vez más masivas hasta las concentraciones nacionales. Por este medio, la Iglesia aparecerá en los medios de comunicación, fundamentalmente en la gran prensa y en la televisión, durante una temporada y la gente hablará de ella. Los funcionarios eclesiásticos adquirirán visibilidad, lo mismo que los templos, sobre todo los más emblemáticos; quizá hasta se ponga de moda algún icono o algún slogan. Pero después de este esfuerzo agotador, además de la satisfacción de sus fautores, ¿no habremos quedado más desfondados, más faltos de sustancia, menos significativos?

No concibo una verdadera conversión sin una proyección real a la sociedad. Pero ¿cuál es la proyección evangélica? Un montaje como el que hemos descrito, ¿no equivale a los signos del cielo que pidieron incesantemente a Jesús y que él se negó de manera sistemática a realizar? Se negó porque esos montajes espectaculares no aportaban salvación, no llevaban a trasformaciones personalizadoras, a un aumento de humanidad. La proyección cristiana debe contener, en todo caso, aumento de humanidad, de fraternidad y nunca puede faltar la entrega a los pobres como predilectos de Dios y destinatarios del reino. Por eso, es 
indispensable la pregunta sobre qué tipo de misión se piensa realizar y, muy en concreto, qué tipo de misión hay que excluir de entrada. Aunque, por supuesto, hay que misionar. Un discípulo no puede no ser un misionero, porque es llamado y elegido para participar de la misión de Jesús.

\section{Papel irrenunciable de la institución eclesiástica}

Ahora bien, aunque el sujeto de todo lo dicho hasta aquí es todo el pueblo de Dios, es imprescindible la contribución cualificada de la institución eclesiástica para ponerlo en marcha. Esto requiere de una conversión específica de sus miembros y una reconversión de la institucionalidad vigente. Los presbíteros y obispos deben subsumirse en el seno del pueblo de Dios, y hacerse cristianos con todos, ser llevados por los laicos y llevarlos a ellos. Su aporte específico es alimentar su vida cristiana, sobre todo trasmitiendo la tradición situadamente, y estimular y coordinar la participación de todos. Todo lo demás, incluida la toma de decisiones en todos los niveles, deberá ser compartido, incluyendo en ese colectivo, y de modo expreso, a las mujeres.

La reconversión institucional pasa por una trasformación del aparato institucional vigente, de manera que sea dinámico, participativo y vehicule la radicalidad evangélica. Pero es también imprescindible la creación de nuevas instituciones, tanto de base, como nacionales y regionales. De base, ya que en las grandes ciudades, las parroquias, aun transformadas, son absolutamente insuficientes, y deben complementarse con grupos por afinidad espiritual, por orientación pastoral y especificidad de sus componentes. Nacionales, porque los organismos de las conferencias episcopales, que deben mantenerse, no pueden representar, ni pueden llegar a tener la densidad suficiente para alimentar a toda la Iglesia de cada país. Regionales, en base a las fronteras históricas y culturales, que no coinciden con las provincias eclesiásticas, para efectuar la inculturación del evangelio a sus respectivos ámbitos.

Para operar esta reconversión institucional y para una acción pastoral eficaz, es indispensable dejar el esquema piramidal anterior y constituir sujetos pastorales colectivos, en gran medida sujetos virtuales, con ayuda del correo electrónico. No hacerlo y persistir en la actual autarquía, es condenarse a un servicio mediocre, que, además, cada vez va a interesar a menos gente, incluso a católicos practicantes. No llevar a cabo la trasformación mental requerida es no definirse por la misión y no querer a la gente.

\section{Sobre la composición de la V Conferencia}

En Venezuela, acabamos de clausurar, el 7 de octubre, el Concilio Plenario Venezolano. Ha sido un verdadero acontecimiento del Espíritu porque, con gozosa sorpresa para todos nosotros, fue un camino sinodal: todos actuamos, no desde nuestros respectivos papeles, como estábamos acostumbrados, sino como 
cristianos, corresponsablemente y con genuina libertad evangélica. Por eso, el resultado es realmente trascendente: muy por delante de donde estamos, a la vez retador e inspirador.

En la metodología, todo fue compartido. Por eso, antes de la votación deliberativa, reservada sólo a los obispos, se daba siempre otra indicativa, donde votaban todos los miembros del concilio. Nunca la segunda votación cambió los resultados de la primera, no porque de hecho así sucedió, sino por la voluntad de que así fuera. Entre los convocados había más laicas y laicos que obispos y más mujeres que obispos.

Si esto acaba de suceder en un país de América Latina en un concilio, mucho más formal que una conferencia general, ¿será mucho pedir que se dé una composición afín, en dicha conferencia? Sería el mayor signo que pudiera darse a nuestra Iglesia y a nuestra región, ya que, entonces, el resto del pueblo de Dios no sería ya únicamente tema y destinatario de lo que diga la jerarquía, sino sujeto que delibera y se da a luz.

Pido encarecidamente tomar en cuenta esta propuesta sobre la composición de la asamblea. 